\title{
Note
}

\section{Improved synthesis of conduritol B epoxide}

\author{
Kevin J. Lee, Steven A. Boyd, and Norman S. Radin* \\ Mental Health Research Institute, The University of Michigan, Ann Arbor, Michigan 48109 (US A.) \\ (Received October 3rd, 1984; accepted for publication, December 6th, 1984)
}

Conduritol B epoxide (CBE, DL-1,2-anhydro-myo-inositol, (8)) is an inactivating inhibitor of several D-glucosidases, particularly the mammalian enzyme which cleaves glucosylceramide. This enzyme is defective in the human genetic disorder Gaucher disease, and the ready availability of the inhibitor would enable investigators to study the disorder in animal models. The synthetic route to $\mathbf{8}$, based on the procedures of Angyal et al. ${ }^{1}$, Nakajima et al. ${ }^{2}$, Nagabhushan ${ }^{3}$, Legler ${ }^{4}$, and Radin and Vunnam ${ }^{5}$, utilized the readily available myo-inositol (1) as starting material. The need for larger amounts and less variable yields led us to study the steps in greater depth, by use of t.l.c. and g.l.c. in time studies. A somewhat improved, faster method is described, in which only two recrystallization steps are required. A design for a large Abderhalden drying pistol is described.

The first step, glycol protection with cyclohexanone, utilized $p$-toluenesulfonic acid as catalyst and benzene as the azeotroping medium. The reaction was made difficult by the low solubility of the reagents in the medium. The reaction proceded beyond the desired point, with formation of an uncertain amount of diacetals and triacetal which required ethanolysis to form the desired 1.2monoacetal $2^{* *}$. It was not clear from the literature how to minimize the formation of myo-inositol (1) by excessive ethanolysis. We replaced benzene with cyclohexane to minimize toxicity, ground myo-inositol (1) in situ with a motor-driven homogenizer to make the particle-size reduction more reproducible, and added dimethyl sulfoxide to increase the miscibility of the reagents. The reaction temperature was brought under control by empirically adjusting the volume of azeotroping agent to produce a reaction temperature of $\sim 110^{\circ}$ while maintaining rapid distillation. This volume is a function of the volumes of the reactants and the glassware

\footnotetext{
*To whom correspondence should be sent at 1103 E. Huron, Ann Arbor, MI 18109, U.S.A.

${ }^{* *}$ Because the acetal compound is formed equally well with the 1,2- and 2,3-glycol groups, all compounds 2-8 have the DL configuration. Only one configuration is given in the scheme of formulas.
} 

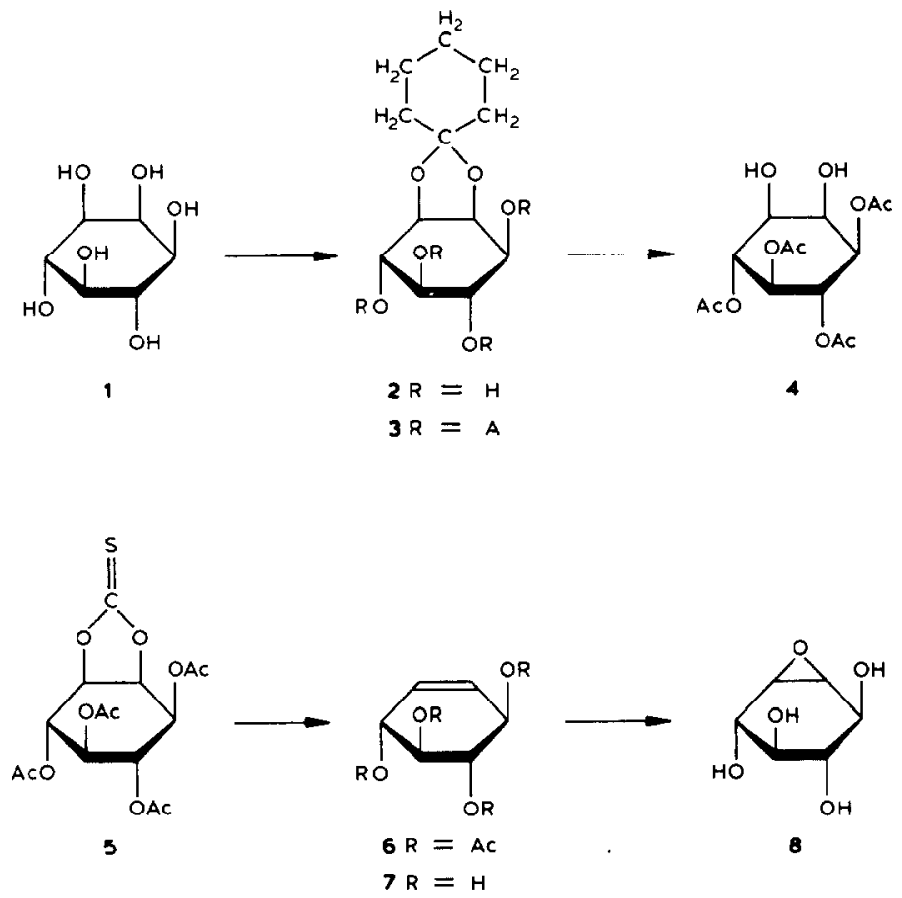

utilized. (It would seem useful to control this variable in all azeotroping reactions.) The ethanolysis step was monitored for optimal yield by t.l.c. The modified procedure allowed us to obtain a yield [corrected for recovered myo-inositol (1)] of $\sim 85 \%$.

In the second step, the previous procedures called for treatment of 2 with pyridine and acetic anhydride at $100^{\circ}$ to form 3,4,5,6-tetra- $O$-acetyl-1,2-O-cyclohexylidene-myo-inositol (3). We found a significant amount of myo-inositol hexaacetate in the product, evidently due to deacetalization. The use of room temperature for the reaction decreased the contamination to $\sim 6 \%$. In the third step, 3 was deprotected by heating at $100^{\circ}$ with $4: 1$ acetic acid-water. Examination of the process by t.l.c. showed that the reaction was far from complete by the end of the recommended period $(3 \mathrm{~h})$ and even by $6 \mathrm{~h}$. Increasing the acidity of the reaction medium with hydrochloric acid greatly increased the rate and extent of formation of myo-inositol 1,4,5,6-tetraacetate (4). Special precautions were necessary to minimize over-hydrolysis during the removal of the reaction medium. The fourth step involved reaction of the diol 4 with $N, N^{\prime}$-thiocarbonyldiimidazole to form the cyclic thiocarbonate ester $\mathbf{5}$. The acylating agent was formed from thiophosgene just before use. This step could be simplified and rendered less hazardous because of the availability of the acylating reagent from Aldrich. In the fifth step, removal of the thiocarbonate group to form conduritol B tetraacetate (6) and, in the next step, removal of the acetyl groups to give conduritol B (DL-cyclohex-5-ene-1,3/2,4-tetrol, 7), were not changed much. The final step, epoxidation 
of $\mathbf{7}$ to form $\mathbf{8}$, was very slow and the final product was found to be contaminated with a significant proportion of unreacted 7 . Following the recommendation of Kishi et al. ${ }^{6}$, we used an elevated temperature, stabilizing the epoxidizing agent with a free radical trapper. This brought the reaction to completion within $12 \mathrm{~h}$, as opposed to 6 days.

\section{EXPERIMENTAL}

General methods. - T.l.c. was performed with Silica gel 60 plates (E. Merck) in $(A)$ 24:7:1 chloroform-methanol-water, $(B)$ 9:1 chloroform-methanol, $(C)$ 30:60:1 hexane-diethyl ether-acetonitrile, $(D)$ 12:3:3:2 ethyl acetate-methanolacetic acid-water ${ }^{7},(E)$ 19:1 chloroform-methanol, and $(F)$ 60:35:8 chloroformmethanol-water. The spots were made visible with a $37 \%$ formaldehyde- $\mathrm{H}_{2} \mathrm{SO}_{4}$ charring spray ${ }^{8}$, and identified by comparison with standards. G.l.c. was performed in a glass-lined column containing $3 \%$ OV- 1 on $60 / 80$ mesh Gas-Chrom Q, with $\mathrm{N}_{2}$ carrier, a $\mathrm{H}_{2}$ flame detector, and a temperature program of $2 \%$ min $\left(150-230^{\circ}\right)$. Alcohols were trimethylsilylated prior to g.l.c. ${ }^{9}$.

1,2-O-Cyclohexylidene-myo-inositol (2). - A suspension of myo-inositol (1) $(75 \mathrm{~g}, 417 \mathrm{mmol})$ in cyclohexanone $(750 \mathrm{~mL})$ and dimethyl sulfoxide $(75 \mathrm{~mL})$ was comminuted in a hood for $60 \mathrm{~min}$ with a steel homogenizer (Brinkmann Polytron set at speed 4). The grinding unit must not contain a Viton seal. The mixture was transferred to a $2-\mathrm{L}$, three-neck flask with a $45 / 50$ joint, containing a $7-\mathrm{cm}$ magnetic stirring "egg", fitted with a graduated Dean-Stark separator. To this was added cyclohexane $(315 \mathrm{~mL})$ and $p$-toluenesulfonic acid monohydrate $(3 \mathrm{~g}, 16 \mathrm{mmol})$, and the system was boiled under reflux for $6 \mathrm{~h}$ in an oil bath, maintained at $150^{\circ}$ in a hood. The volume of cyclohexane in the system was adjusted by withdrawal from the Dean-Stark separator to produce an internal temperature of $110-111^{\circ}$. The water formed $(\sim 32 \mathrm{~mL})$ was drawn off occasionally to keep the boiling temperature fairly constant.

The theoretical yields of water are $7.5 \mathrm{~mL}$ for the monoacetal, $15 \mathrm{~mL}$ for the diacetal, and $22.5 \mathrm{~mL}$ for the triacetal. Only $0.3 \mathrm{~mL}$ of water originated from the catalyst and a very small amount from myo-inositol, as shown by weighing commercial and dried materials. The formation of extra water has been attributed to self-condensation of cyclohexanone ${ }^{1}$, presumably via enolization to form cyclohexanone dicyclohexenyl acetal.

The flask contents were kept overnight at $5^{\circ}$, the crystals of unreacted myoinositol (1) filtered off and washed with abs. ethanol $(450 \mathrm{~mL})$, and the washing plus filtrate was stirred at room temperature. A dense suspension of crystalline 2 formed rapidly. After $3 \mathrm{~h}$, triethylamine $(2.8 \mathrm{~mL})$ was added to stop the ethanolysis and the mixture stirred in ice for $1 \mathrm{~h}$. The crystals were washed on the filter with cold abs. ethanol $(150 \mathrm{~mL})$. They had a wet appearance, possibly due to entrapped dimethyl sulfoxide; they were homogenized in hexane $(500 \mathrm{~mL})$ for $10 \mathrm{~min}$ with the Polytron as described earlier. The crystals were rinsed on the filter with a little more hexane and dried in vacuo in the presence of Bio-Rad XAD-2 resin and $\mathrm{P}_{2} \mathrm{O}_{5}$. 
T.l.c. of the reaction-mixture filtrate with solvent $A$, immediately after dilution with ethanol and neutralization, showed that myo-inositol (1) was absent. Several substances were visible, with $1\left(R_{\mathrm{F}} 0.22\right)$ comprising only a small proportion. The major products were a pair of dark, overlapping spots at $R_{\mathrm{F}} 0.65$ and 0.69 (and a minor spot at 0.61 ), presumably a mixture of isomeric diacetals. A fastermoving spot $\left(R_{\mathrm{F}} 0.78\right)$ had an atypical, deep-pink color. (Virtually every substance detected with this almost universal reagent yields a gray spot.) This low-polarity component is probably the self-condensation product from cyclohexanone. It was unaffected by the ethanol treatment.

During ethanolysis, the intensity of the monoacetal spot increased while the three slower-moving spots diminished greatly. Three hours of reaction time resulted in appearance of a small proportion of myo-inositol (1) at the t.l.c. origin, showing, as noted before ${ }^{1}$, that some 2 was also undergoing ethanolysis. While some of the diacetal was still present at this time, a time of $3 \mathrm{~h}$ seemed a good compromise between the opposing reactions. One could obtain a higher yield by occasionally removing the crystals from the reaction medium. (Incidentally, we found that the spot of 1 migrated downward if the t.l.c. plates were nearly vertical during the spraying step. Evidently the water in the sprays, driven down by gravity, caused migration of the spot.) myo-Inositol (1) was further identified with solvent $D\left(R_{\mathrm{F}} 0.19\right)$.

Compound $2(83 \mathrm{~g}, 320 \mathrm{mmol} ; 77 \%$ yield, $85 \%$ yield corrected for $7 \mathrm{~g}$ of recovered $\mathbf{1}$ ) contained only a small proportion of $\mathbf{1}$.

3,4,5,6-Tetra-O-acetyl-1,2-O-cyclohexylidene-myo-inositol (3). - Acetylation of 2 at $100^{\circ}$ produccd the tetraacetate 3 containing a significant proportion of myo-inositol hexaacetate $\left(C, R_{\mathrm{F}} 0.30 v s .0 .20\right.$ for 3$)$. When the acetylation was carried out at room temperature, the hexaacetate spot was much paler. Compound $2(50 \mathrm{~g}, 192 \mathrm{mmol})$, pyridine $\left(283 \mathrm{~mL}\right.$, filtered from $\left.\mathrm{CaH}_{2}\right)$, and acetic anhydride $(333 \mathrm{~mL})$ were stirred in a 2-L flask overnight. The yellowish solution was cooled in ice, methanol $(150 \mathrm{~mL}, 2.5 \mathrm{~mL} / \mathrm{min})$ was added with a peristaltic pump, slowly enough to maintain the flask content at $25^{\circ}$. The solution was next added over a 30 -min period via a separatory funnel to ice-water $(1500 \mathrm{~mL}$ in a $4000-\mathrm{mL}$ plastic beaker) while stirring with a metal propeller to break up the lumps that formed. (Too rapid an addition produced a large, amorphous ball.) The very cloudy suspension of 3 was filtered off, washed well with water, and dried in the presence of $\mathrm{CaCl}_{2}\left(75 \mathrm{~g}, 90 \%\right.$ yield, m.p. $\left.111-112^{\circ}\right)$. G.l.c. showed two peaks, contaminating hexaacetate $\left(R_{\mathrm{T}} 1070 \mathrm{sec}, 6 \%\right.$ of the total area) and $3\left(R_{\mathrm{T}} 1600 \mathrm{sec}\right)$.

1,4,5,6-Tetra-O-acetyl-myo-inositol (4). - Compound $3(40 \mathrm{~g}, 87.6 \mathrm{mmol})$ was heated in a 2-L flask in an oil bath with acetic acid $(64 \mathrm{~mL})$ and water $(16 \mathrm{~mL})$. When the internal temperature reached $100^{\circ}, 0.1 \mathrm{M} \mathrm{HCl}(8 \mathrm{~mL})$ was added. After $45 \mathrm{~min}$ at this temperature, the solution was cooled rapidly and diluted with $8 \mathrm{mM}$ $\mathrm{NaOH}(200 \mathrm{~mL}, 2 \mathrm{~mol} / \mathrm{mol} \mathrm{HCl})$ to make the mixture less acidic. The liquid was lyophilized $(\sim 12 \mathrm{~h})$ with a Dry-Ice trap using $\mathrm{KOH}$ pellets in a tube between the pump and condenser trap to protect the pump (and sample!). Further drying was 
done in vacuo in the presence of $\mathrm{KOH}$, but some acetic acid could still be detected by odor.

A t.l.c. time-study showed that the inclusion of $\mathrm{HCl}$ in the reaction medium catalyzed a little over-hydrolysis, with formation of a polar material $\left(R_{\mathrm{F}} 0.14, B\right.$, presumably inositol diacetate) and a trace of two barely-separated materials $\left(R_{\mathrm{F}}\right.$ $0.30)$. A small proportion of unreacted $3\left(R_{\mathrm{F}} 0.76\right)$ was still visible, but the major component was $4\left(R_{\mathrm{F}} 0.35\right)$. The conditions described in the previous paragraph constitute a satisfactory compromise between non- and over-hydrolysis.

To extract 4 from unhydrolyzed, residual $\mathbf{3}$, the solid material was homogenized as in step 1 with water $(600 \mathrm{~mL})$ for $10 \mathrm{~min}$. The mixture was filtered off and rinsed with water (producing filtrate $\mathrm{A}$ ) and the filter cake was suspended in boiling water $(150 \mathrm{~mL})$ to extract additional 4. Heating at this stage did not produce hydrolysis of 4 because so little acid was now present. About $6 \mathrm{~g}$ of 3 were recovered from the funnel after hot filtration. Cooling this filtrate yielded $4(12 \mathrm{~g})$. Additional 4 was obtained from filtrate $A$, which was de-ionized by passage through a column of Amberlite mixed-bed resin (MB-3, $0.5 \times 51 \mathrm{~cm}$ ), followed by a water rinse $(75 \mathrm{~mL})$. Lyophilization of the combined effluents yielded $4(15 \mathrm{~g}, 83 \%$ yield after combining the two portions, $97 \%$ yield corrected for recovered $\mathbf{3}$ ).

The recovered $\mathbf{3}$ contained the contaminating inositol hexaacetate originally present in the preparation. Both compounds had the same $R_{\mathrm{F}}$ in $B$, but separated well in $C$ (hexacetate, $R_{\mathrm{F}} 0.20 ; 3, R_{\mathrm{F}} 0.30$ ). A test with standard hexacetate showed that it was unaffected by the acid hydrolysis, so its concentration in $\mathbf{3}$ was now higher than before deacetalization. Compound $\mathbf{4}$ was free of hexaacetate, but a small proportion of some impurity was seen by t.I.c., possibly inositol diacetate.

In our initial trials, the acetic acid hydrolysis mixture was rotoevaporated in vacuo to a small volume. Examination of the product by t.l.c. $(B)$ showed that additional polar material had formed during evaporation, even though the evaporator bath had been kept at $35^{\circ}$. Even more breakdown occurred at this step when $\mathrm{HCl}$ was present. The problem was solved by raising the $\mathrm{pH}$ a little with $\mathrm{NaOH}$ and by removing the solvent at a low temperature (by lyophilization). The small amounts of sodium chloride and acetate in the dry product, plus some residual acid, were removed with a small column of mixed ion-exchange resins.

Conduritol $B$ tetraacetate (6). - Diol $4(46 \mathrm{~g}, 132 \mathrm{mmol})$ was dried in a modified Abderhalden pistol, by immersing the sample in a $1000-\mathrm{mL}$ flask in a $70^{\circ}$-oil bath. The joint of the flask was connected to a wide glass tee made from: (a) an inner $24 / 40$ joint, for the reaction flask, (b) a high-vacuum stopcock for the vacuum pump, and (c) an outer $24 / 40$ joint, which was connected to a $250-\mathrm{mL}$ flask containing $\mathrm{P}_{2} \mathrm{O}_{5}$. The sample was heated under high vacuum overnight and acetone (200 mL, dried in the presence of $\mathrm{B}_{2} \mathrm{O}_{3}$ overnight) was distilled into the flask. To this were added a boiling stick and bis(imidazol-1-yl)thione $(30 \mathrm{~g}, 150 \mathrm{mmol}$, based on the label purity of $90 \%$ ). A reflux condenser, dricd at $100^{\circ}$, was connected and the air was replaced with $\mathrm{N}_{2}$ (Firestone valve. Aldrich Chemical Co.). The yellow solution was boiled under reflux for $3 \mathrm{~h}$ and rotoevaporated to give a syrup. The 
residue was dissolved in chloroform $(400 \mathrm{~mL})$ and the solution washed with $1 \%$ $\mathrm{HCl}(4 \times 400 \mathrm{~mL})$ and sat. $\mathrm{Na}_{2} \mathrm{CO}_{3}(2 \times 400 \mathrm{~mL})$. The dried solution $\left(\mathrm{Mg}_{2} \mathrm{SO}_{4}\right)$ was evaporated to give a resin, which yielded 5 on recrystallization from $500 \mathrm{~mL}$ of methanol ( $28 \mathrm{~g}, 54 \%$ yield), m.p. $167-168^{\circ}$. T.l.c. of $5(E)$ showed only one spot, $R_{\mathrm{F}} 0.29$, made visible particularly well with $\mathrm{I}_{2}$.

To compound 5 ( $28 \mathrm{~g}, 72 \mathrm{mmol}$, dried in vacuo in the presence of $\mathrm{P}_{2} \mathrm{O}_{5}$ ) in a dried $500-\mathrm{mL}$ flask was added trimethyl phosphite $(200 \mathrm{~mL})$. After being boiled for $5 \mathrm{~h}$ under reflux in $\mathrm{N}_{2}$, the mixture was reduced to $\sim 75 \mathrm{~mL}$ by distillation at atmospheric pressure in a hood. It was reduced further to a syrup by rotoevaporation; this step should be done with an aspirator located in a hood to control the odor. The residue (6) was triturated with water $(250 \mathrm{~mL})$ to hydrolyze residual phosphorus compounds, kept in the cold overnight, collected by filtration, and washed well with hexane. The product (dried in vacuo in the presence of $\mathrm{KOH}$; $17 \mathrm{~g}, 54 \mathrm{mmol}, 75 \%$ yield), m.p. $84-85^{\circ}$, showed one spot $\left(C, R_{\mathrm{F}} 0.33\right)$ and one peak with g.l.c. $\left(R_{\mathrm{T}} 470 \mathrm{sec}\right)$. Rotoevaporation was slow, so most of the reagent was removed at atmospheric pressure. Attempts to remove the phosphorus compounds by hydrolysis, instead of by distillation, were unsatisfactory.

Conduritol $B(7)$. - According to the method previously described ${ }^{5}, 6(17 \mathrm{~g}$, $54 \mathrm{mmol})$ and triethylamine $(17 \mathrm{~mL})$ were dissolved in $7: 3(\mathrm{v} / \mathrm{v})$ methanol-water $(170 \mathrm{~mL})$, the solution was kept overnight, the solvent removed by rotoevaporation, and the residue dried in vacuo in the presence of $\mathrm{KOH}(8 \mathrm{~g}, 54 \mathrm{mmol}, 100 \%$ yield), m.p. $195-196.5^{\circ}$; t.l.c. showed only one spot $\left(R_{\mathrm{F}} 0.32, F\right)$ and g.l.c. one peak $\left(R_{\mathrm{T}} 605 \mathrm{sec}\right)$.

Conduritol $B$ epoxide (DL-1,2-anhydro-myo-inositol) (8). - T.1.c. of 8 produced previously 5 showed two close spots $\left(R_{\mathrm{F}} 0.27\right.$ and $\left.0.32, F\right)$. The upper spot, corresponding to 7, was black and appeared quickly; the lower one, brown, appeared slowly. The latter gave a positive reaction for epoxides ${ }^{10}$. Retreatment of a sample with chloroperoxybenzoic acid for three additional days eliminated the upper spot, suggesting that the reaction was incomplete. Semiquantitative t.l.c. showed that $\mathbf{7}$ is much more sensitive than 8 to the spray and g.l.c. analysis $\left(R_{\mathrm{T}}\right.$ of $8825 \mathrm{sec}$ ) indicated $\sim 17 \%$ of contaminant. Kishi et al. ${ }^{6}$ reported that unreactive olefins could be epoxidized in dichloromethane by use of a high temperature in the presence of a radical inhibitor, such as 4,4'-thiobis(6-tert-butyl-3-methylphenol). The similar, more available 4',4-thiobis(2-tert-butyl-6-methylphenol) (Aldrich) was also effective in boiling methanol, and iodimetric titration of a blank reaction showed that the peroxy acid was stable under this condition. Thus, 7 (4.3 g, 30 mmol), sulfide $(0.1 \mathrm{~g})$, and 3-chloroperoxybenzoic acid $(15.2 \mathrm{~g}, 75 \mathrm{mmol}, 85 \%$ pure) in methanol $(500 \mathrm{~mL})$ were heated under reflux in an oil bath with a magnetic stirrer for $12 \mathrm{~h}$. The yellow solution was rotoevaporated to dryness and the residue washed with diethyl ether $(3 \times 250 \mathrm{~mL})$. Compound 8 crystallized from warm abs. ethanol by cooling to $-20^{\circ}(4 \mathrm{~g})$, one spot by t.l.c., m.p. $155-6^{\circ}$ (uncorr.). The filtrate yielded an additional $0.5 \mathrm{~g}$ by addition of ether $(50 \mathrm{~mL})$ and cooling again (total yield, $27 \mathrm{mmol}, 90 \%$ ).

Attcmpts to crystallize 8 from a water-containing solution yielded only oils. 


\section{ACKNOWLEDGMENTS}

This work was supported by grants HD 05515 (to Dr. Robert McCluer), NS 03192, and HD 07406 from the National Institutes of Health. Part of the work, with Dr. Boyd, was done while the senior author was on sabbatical leave at the University of California at Los Angeles and the authors are indebted to Dr. Wayne $\mathrm{J}$. Thompson for his cooperation in furnishing laboratory facilities. Drs. McCluer, James Evans, and David Newburg furnished helpful comments on the last step.

\section{REFERENCES}

1 S. J. Angyal, G. C. Irving, D. Rutherford, and M. E. TAte, J. Chem. Soc., (1965) 6662-6664.

2 M. Nakajima, I. Tomida, N. Kurihara, And S. TakeI, Chem. Ber.. 92 (1959) 173-178.

3 T. L. Nagabhushan, Can. J. Chem., 48 (1970) 383-384.

4 G. LEGLER, Methods Enzymol., 46 (1977) 368-381.

5 N. S. Radin and R. R. Vunnam, Methods Enzymol., 72 (1981) 673-684.

6 Y. Kishi, M. Aratani, H. Tanino, T. Fukuyama, and T. Goto, Chem. Commun., (1972) 64-65.

7 T. Kartnig AND O. Wegschaider, J. Chromatogr., 61 (1971) 375-377.

8 G. Rouser, S. Fleischer, and A. Yamamoto, Lipids, 5 (1970) 494-496.

9 C. C. Sweeley, R. Bentley, M. Makita, and W. W. Wells, J. Am. Chem. Soc., 85 (1963) 24972507.

10 F. Oesch, D. M. Jerina, And J. Daly, Biochim. Biophys. Acta, 227 (1971) 685-691. 